\title{
Production Forecast Studies for Oil Well Performance Prediction and Field Devel- opment Scenario Using Decline Curve Analysis in Multilayer Reservoirs: A Case Study of Field Z
}

\author{
Cahyadi Julianto *, Hidayat Tulloh, Aldi Priambodo, Muhammad Rizky Nugroho, Haykal Kurniawan \\ Department of Petroleum Engineering, Universitas Pembangunan Nasional "Veteran” Surabaya, East Java, \\ Indonesia
}

*Corresponding author:

E-mail: cjulianto97@gmail.com

\begin{abstract}
Field $\mathrm{Z}$ is located in the south Sumatra region with a reservoir located in the Talang Akar and Baturaja formation. Field $\mathrm{Z}$ has 9 layers and 29 wells have been produced until 2019. Based on the calculation of the JJ Arps method (water drive), the recovery factor of Layer 1 is $42,834 \%$, RF layer 2 is $42.62 \%$ and layer 6 is $40.16 \%$. This Arps can be estimated how much oil can be produced from OOIP owned by the reservoir. From these results obtained volumetric In-Place magnitude at Layer $1=11.52 \mathrm{MMSTB}$, Layer $2=17.99 \mathrm{MMSTB}$, and Layer $6=7.50$ MMSTB. But the recovery factor of the $\mathrm{Z}$ field is currently only $9.67 \%$ in the last year of 2019. From this statement, it is necessary to develop a field development scenario. The method in this paper is to take data from the field and then the data is processed to forecast production using a decline curve analysis (DCA) using Oil Field Management software. After forecasting production, a scenario is then performed to extend the production life of the well.
\end{abstract}

Keywords: Decline curve analysis, field Z, field development scenario, recovery factor

\section{Introduction}

Over time, oil production in a field will decrease due to several factors such as a decrease in reservoir pressure or a production problem in a well (Hook, Hirsch, \& Alektett, 2009). This happened at field Z. Field $\mathrm{Z}$ is located on the northeast flank of the North Sumatra Basin. Field Z is located in two reservoirs namely the Talang Akar formation and the Batu Raja formation. The largest volumetric oil reserves in field $\mathrm{Z}$ are located in the Baturaja formation. Field $\mathrm{Z}$ began production from 1975 until the end of 2019 and experienced a decline in oil production after the peak of production in 2003.

To find out the performance of $\mathrm{Z}$ field production in a particular year, an analysis was carried out using methods such as the Decline Curve Analysis (DCA) method (Tan, Zuo, \& Wang, 2018). DCA is the most used method to predict oil well or gas well production based on historic production performance. Usually, DCA is done on rate vs. time or rate vs. cumulative oil/gas data (Ahmed \& Hasan, 2018). Based on the nominal decline rate change with the time, the production decline trend of the well is categorized into three types (exponential, hyperbolic, and harmonic declines) (Manda \& Nkazi, 2020). Using these decline trends production scenarios are estimated for planning future operations and finances of the field.

After conducting an analysis using DCA in field Z, we can forecast production until 2040 and create several field development scenarios to maintain oil or gas production rates in field Z (Solis, Chi-Chim, \& Sheremetov, 2015). Scenario development of Field $Z$ that may be applied include reopening wells, adding well infill, as well as water injection. This is done to increase the oil rate and increase the value of the Recovery Factor. The scenario plan will be developed from 2020 to 2040.

How to cite:

Julianto et al. . (2020). Production forecast studies for oil well performance prediction and field development scenario using decline curve analysis in multilayer reservoirs: A case study of field Z. ${ }^{\text {st }}$ International Conference Eco-Innovation in Science, Engineering, and Technology. NST Proceedings. pages 133-139. doi: 10.11594/ nstp.2020.0520 


\section{Research Method}

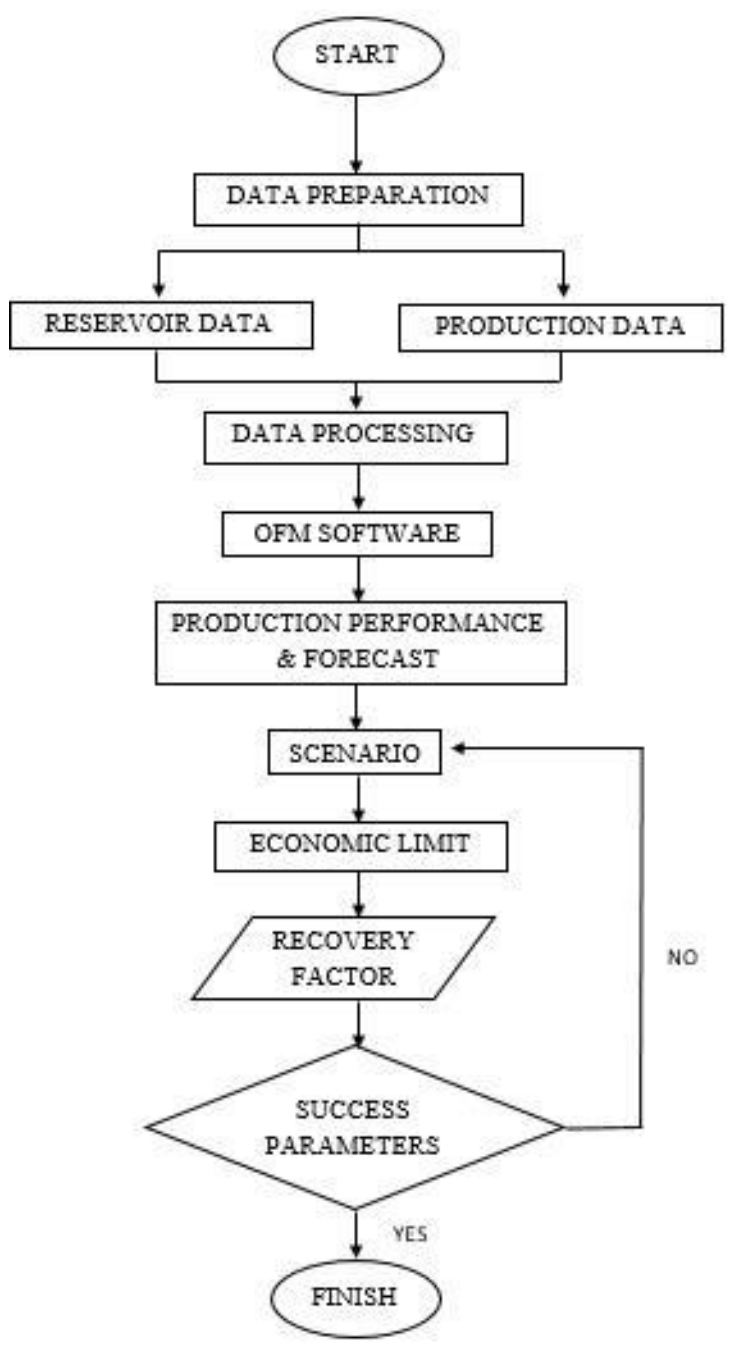

Figure 1. Flowchart

Before carrying out the $\mathrm{Z}$ field development scenario, steps are first taken from data processing to the determination of recovery factor values. The earliest step is to prepare production and reservoir data. Production data include oil, water, water cut, and GOR production rates. While the reservoir data include data on reservoir rock characteristics and reservoir fluid characteristics (Ahmed et al., 2018). After that, the data is processed to calculate the initial reserves and recovery factor using the JJ method. Arps Processing of production data is carried out for input to the Oil field Manager (OFM) Software (Salih et al., 2016). In OFM Software, a reservoir behavior chart can be determined and production forecasting can be done in a particular year. The next step is to develop the $\mathrm{Z}$ field scenarios on layers 1,2, and 6 until 2040. If the oil production rate in the scenario until 2040 is below the economic limit, wells on that layer must be suspended. Besides, if the recovery factor is small, the $\mathrm{Z}$ field development scenario on the layer must be replaced or added so that the Recovery Factor value is large and of course the oil production rate is above the economic limit.

\section{Results and Discussion Producation forecast}

The wells in Field $Z$ have been active since 1975. When viewed from reserves and OOIP, reservoirs in Field $\mathrm{Z}$ have substantial reserves. The property of the reservoir is quite good with a porosity value of 
around $18-20 \%$ per layer, and high permeability. The driving mechanism for this reservoir is the water drive. The reduction in reservoir pressure ranges from $2-5 \%$ per year. The following is a graph of $Z$ field production until the end of 2019.

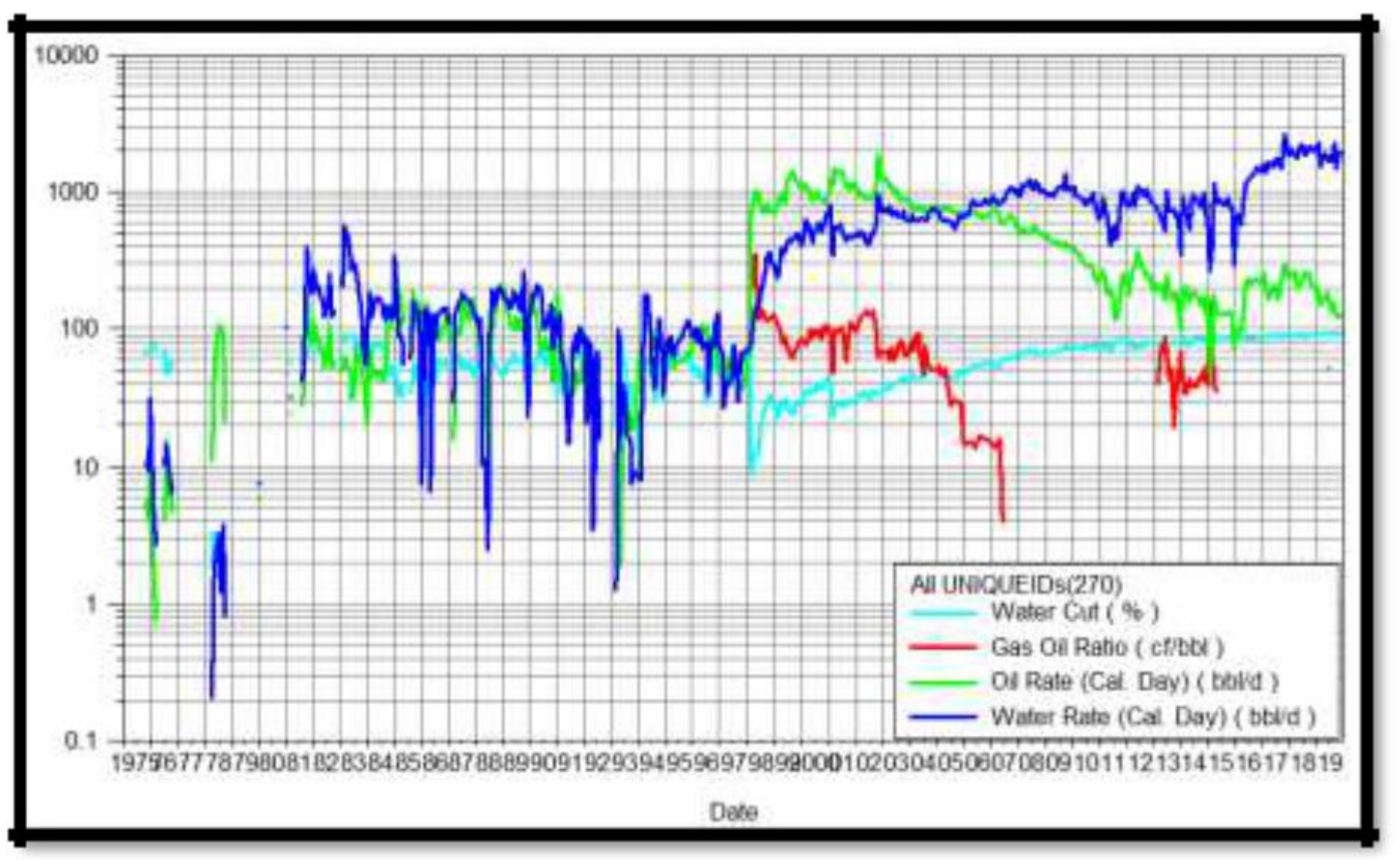

Figure 2. Chart of production Field Z

In making production forecasting the Decline curve method is carried out because this method can be done when the production of a field has reached its maximum point. Decline curve analysis is one way to find out reservoir behavior by analyzing the production rate decline curve. This method is used to predict oil production can determine the age of production of a field. One important factor decline curve analysis is used in this field because there are already production data. Determination of the downward trend in production is very important and will determine the outcome of the DCA. To analyze and determine the line drawn on a decline curve that is to determine the period on the production decline curve at a certain time where the decline in production must be caused naturally, the most important requirement in determining the period of production decline trend for DCA is the number of active wells must be constant for DCA per layer and no change in production methods.

The decline curve analysis method used is an exponential type with a value of $b=0$ and hyperbole, this is based on the results of the analysis and calculation of production data provided so that it can be seen a downward trend at a certain period with the decline curve conditions that must be met such as the number of active wells must be constant, there are no problems in the wellbore, there is no change in the choke or change in the capacity of the lifting mechanism and the change in completion for the same DCA. The decline in the line is based on a decrease in production when the number of production wells is constant.

1. In Layer 1, the withdrawal of the line is done by the exponential method because the value of $b$ obtained from calculations using the trial and error method is the smallest value at value $b=0$

2. In Layer 2, the withdrawal of the line is done by hyperbole method because the value of $b$ obtained from calculations using the trial and error method is the smallest value at value $b=0.2$

3. In Layer 6, the withdrawal of the line is done by the exponential method because the value of $b$ obtained from calculations using the trial and error method is the smallest value at value $b$

So, we get the trend decline of each layer as follows: 


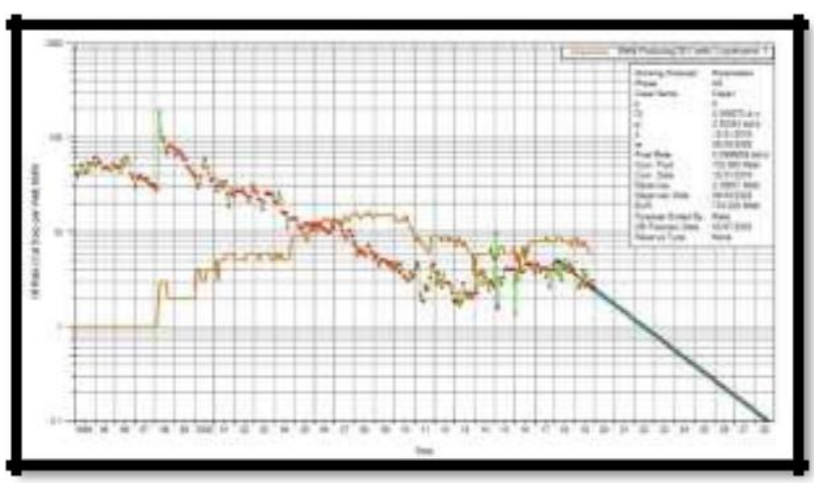

(a)

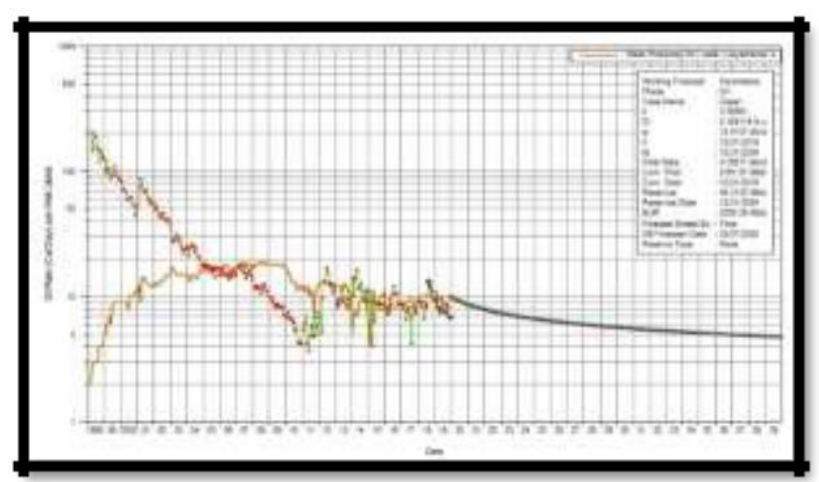

(b)

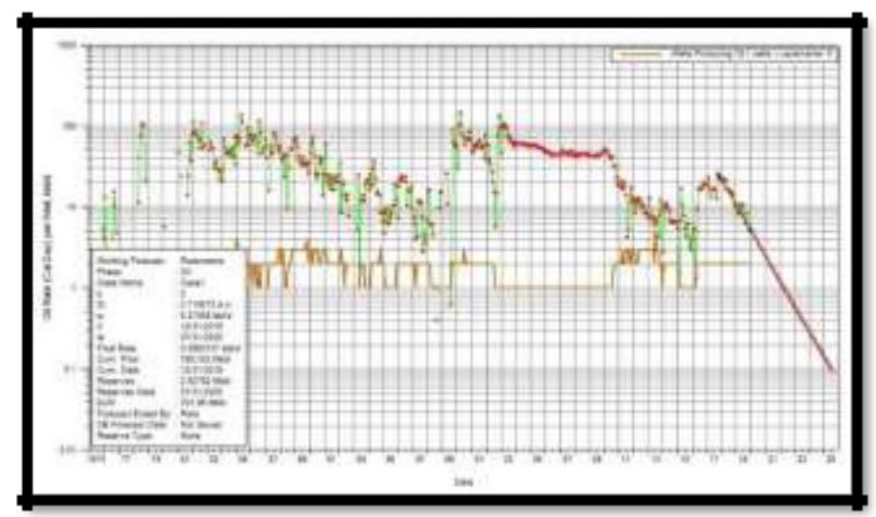

(c)

Figure 3(a) DCA Layer 1, fig. 3(b) DCA Layer 2, fig. 3(c) DCA Layer 6

Layers 1 and 2 are layers with the same reservoir while layer 6 is a different reservoir layer. Infield $\mathrm{Z}$ the production history in the 1.2 and 6 layers is also good with a high rate and $\mathrm{Rf}$ that is not too high so it can still be developed. The downward trend of decline in field $\mathrm{Z}$ is also good so that the lifetime of this field will have a longer period. Based on the results of the Decline curve analysis above, tabulations can be made regarding the condition of each layer in Field $\mathrm{Z}$ in the future development prospects. If the Field $\mathrm{Z}$ layer is re-produced until it reaches the economic limit, the reserve that can be produced with existing technology at that time is $48.7353 \mathrm{MBbl}$ with a total EUR of $3733.37 \mathrm{MBbl}$. When compared between EUR results of decline curve analysis with EUR based on the calculation of Recovery Factor (JJ Arps) for reservoirs with water drive booster mechanism contained in table 3 Field $\mathrm{Z}$ requires a development scenario both Workover and even the addition of new wells (Infill) to increase acquisition oil on the surface so that the EUR (JJ Arps) can be reached.

Table 1.Comparison of EUR DCA and EUR RF Calculations (JJ Arps)

\begin{tabular}{ccccc}
\hline Layer & $\begin{array}{c}\text { Reserve (OOIP) } \\
\text { Bbl }\end{array}$ & $\begin{array}{c}\text { RF (JJ } \\
\text { Arps) }\end{array}$ & $\begin{array}{c}\text { EUR } \\
\text { Bbl }\end{array}$ & $\begin{array}{c}\text { EUR (Decline } \\
\text { Analysis) bbl }\end{array}$ \\
\hline Layer 1 & 11510000 & $42.83 \%$ & 4933218 & 735202 \\
Layer 2 & 17980000 & $42.62 \%$ & 7666739.6 & 2206208 \\
Layer 6 & 7500000 & $40.15 \%$ & 3219273.6 & 791960 \\
\hline
\end{tabular}




\section{Scenario of field $Z$}

Infield $\mathrm{Z}$, the recommended types of field development scenarios are well reopening, infill well addition, and water injection. The scenario is carried out on layers that are considered prospects to be developed, namely layers 1,2, and 6 . The scenario is carried out based on each layer. Each layer will be developed based on suitable scenarios to be carried out to increase the value of the oil production rate and increase the recovery factor. Scenario planning and production forecasting will be carried out until the end of 2040.

The amount of decline rate follows the decline rate of each layer as used in the calculation of existing reserves. The economic limit used in production forecasting is 5 BOPD per well. The proposed scenario for developing Field $\mathrm{Z}$ besides considering the aspects mentioned above is also based on consideration of acquisition factors, water saturation distribution, permeability, porosity, and pressure.

The following is a scenario for developing field $\mathrm{Z}$ that allows it to be developed

a. Reopening well

For many old wells that have water cut close to $100 \%$ or even reach $100 \%$, it is necessary to reopen the layer. The good recommendations that can be done on field $\mathrm{Z}$ in the field development scenario include X-10, X-11, X-30, X-31, X-29 for layer 1, wells X-11, X-18, and X-29 for Layer 2, X-4, $\mathrm{X}-10$, and $\mathrm{X}-15$ for layer 6 .

b. Infill wells

Determination of infill well points is done by analysis on the bubble map in OFM Software. The infill well recommendations are based on the results of the analysis on the bubble map and subsurface map include well Z-1 in layer 1 and Z-2 in layer 2.

c. Water injection

Water injection wells in field development $\mathrm{Z}$ did not do drilling again on the grounds of saving costs. The selected water injection wells come from wells with $100 \%$ water cut (no longer producing oil until the end of 2019). The good recommendations are based on the results of the analysis on water cut include well X-13 in layer 1, well X-9, X-16 in layer 2, and well X-28, X-3 in layer 6.

\section{Analysis of scenario}

Base on the analysis chart in OFM Software, then the curve will give the information about the oil rate in each layer 1, 2, and 6 until the end of the 2040th year.

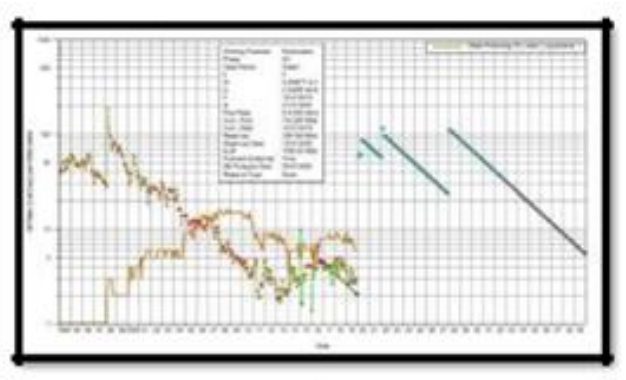

(a)

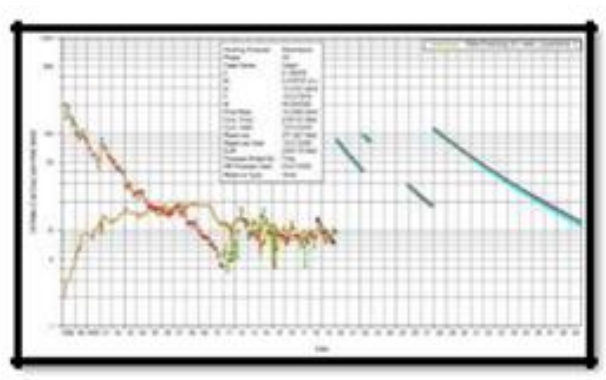

(b)

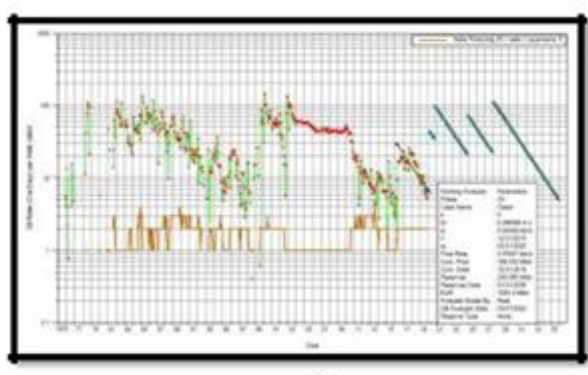

(c)

Figure 4. (a) Curve Scenario Of Layer 1, fig. 4(b) Curve Scenario Of Layer 2, fig. 4(c) Curve Scenario Of Layer 6 
At Layer 1 the value of $b$ is 0 so the DCA equation uses exponential or straight lines. Whereas the rate of oil at the end of the scenario year is $5,413 \mathrm{bbl} / \mathrm{d}$. The cumulative production is $732805 \mathrm{bbl}$. So the EUR value obtained is $1058830 \mathrm{bbl}$. At layer 2 the value of $b$ is 0.2 so the DCA equation uses hyperbolic. The rate of oil at the end of the scenario year is $12.23 \mathrm{bbl} / \mathrm{d}$. The cumulative production is $2161970 \mathrm{bbl}$. So that the EUR value obtained is $2433790 \mathrm{bbl}$. At Layer 6 the value of $\mathrm{b}$ is 0 so the DCA equation uses exponential or straight lines. The cumulative production is $789,332 \mathrm{bbl}$. Whereas the rate of oil at the end of the scenario year is $5 \mathrm{bbl} / \mathrm{d}$. So the EUR value obtained is $1025400 \mathrm{bbl}$. Besides, the Recovery Factor value can also be obtained in CDA analysis using OFM Software as follows:

Table 2. Value recovery factor forecast for total field $\mathrm{Z}$

\begin{tabular}{cccccc}
\hline $\begin{array}{c}\text { Np Forecast } \\
\text { Bbl }\end{array}$ & Np History & Np Total & OOIP Total & RF Forecast & RF Base case \\
\hline 5503565 & Bbl & Bbl & Bbl & & \\
\hline & 5254062.566 & 10757627.57 & 51247355.09 & $20.9916 \%$ & $10 \%$ \\
\hline
\end{tabular}

From the above table, it can be seen through the calculation of the Recovery Factor values in the base case and Recovery Factor Forecast. The Recovery Factor Base case value is $10 \%$ while the Recovery Factor Forecast value is $20.99 \%$. Adding a Recovery Factor value after scenarios in layers 1, 2, and 6 gives an additional value of $10.99 \%$ in the $\mathrm{Z}$ field.

Table 3. Value recovery factor forecast layers 1,2 , and 6

\begin{tabular}{cccccc}
\hline Layer & $\begin{array}{c}\text { Np Forecast } \\
\text { Bbl }\end{array}$ & $\begin{array}{c}\text { Np History } \\
\text { Bbl }\end{array}$ & $\begin{array}{c}\text { Np Total } \\
\text { Bbl }\end{array}$ & $\begin{array}{c}\text { OOIP Total } \\
\text { Bbl }\end{array}$ & RF Forecast \\
\hline Layer 1 & 1479975 & 750581.1833 & 2230556.183 & 11517026.3 & $19 \%$ \\
Layer 2 & 1941040 & 2197929.282 & 4138969.282 & 17987855.8 & $23 \%$ \\
Layer 6 & 2033209 & 378469 & 2411678 & 7503793.74 & $32 \%$ \\
\hline
\end{tabular}

From the table above we can find out the magnitude of each Recovery Factor value at layers 1, 2, and 6. The Recovery Factor value calculated in the table above is the Recovery Factor forecast value, which is the results of the field development scenario until 2040.

\section{Conclusion}

From the results of the discussion above, it can be summarized as follows

1. Field $\mathrm{Z}$ is a field with a multilayer reservoir, there are 2 reservoirs in the Batu Raja and Talang Akar formations and consist of 9 layers and 29 wells

2. The value of the productivity of the layer in the $\mathrm{Z}$ field that may be developed further is layer 1,2 , and 6 using the Decline Curve Analysis (DCA) method with the Oil Field Manager Software

3. Scenario development for field $\mathrm{Z}$ is carried out from 2020 to 2040 by reopening wells, adding infill wells, and water injection

4. The Recovery Factor Base case value is $10 \%$ while the Recovery Factor Forecast value is $20.99 \%$ and the addition of the Recovery Factor value after the scenarios on layers 1, 2, and 6 gives an additional value of $10.99 \%$ in the $\mathrm{Z}$ field.

\section{References}

Ahmed, N., Kausar, T., Khalid, P., Akram, M. S. (2018). Assessment of reservoir rock properties from rock physics modeling and petrophysical analysis of borehone logging data to lessen uncertainty in formation characterization in ratana gas field, Northern Potwar, Pakistan. Journal of the Geological Society of India, 91(6), 736-742. doi: 10.1007/s12594-018-0932-8

Ahmed, R., \& Hasan, M. A. (2018). Evaluation of well performance of titas gas field by decline curve analysis using type curves. Journal of Nature Science and Sustainable Technology, 12(2), 89-196. 
Hook, M., Hirsch, R., \& Aleklett, K. (2009). Giants oil field decline rates and their influence on world oil production. Energy policy, 37(6), 2262-2272. doi: $10.1016 /$ j.enpol.2009.02.020

Manda, P., \& Nkazi, D. B. (2020). The evaluation and sensitivity of decline curve modelling. Energies, 13, 2765. doi:10.3390/en13112765

Salih, O. A. N., Tantawy, M., ELayouty, S., \& Abd hady, A. (2016). Oil reserves evaluation and field development plan of hakim oil field in Libya. Journal of Petroleum and Mining Engineering, 18(1), 39-53.

Solis, J. F., Chi-Chim, M., \& Sheremetov. (2015). Forecasting oil production time series with a population-based simulated annealing method. Arabian Journal for Science and Engineering, 40(4), 13-19. doi: 10.1007/s13369-015-1587-Z

Tan, L., Zuo, L., \& Wang, B. (2018). Methods of decline curve analysis for shale gas reservoirs. Energies, 11(3),552. DOI: $10.3390 /$ en 11030552 